\title{
An analysis of health promotion materials for Dutch truck drivers: Off target and too complex?
}

\author{
Anniek Boeijinga ${ }^{\mathrm{a}, *}$, Hans Hoeken $^{\mathrm{b}}$ and José Sanders ${ }^{\mathrm{a}}$ \\ ${ }^{a}$ Centre for Language Studies, Radboud University Nijmegen, The Netherlands \\ ${ }^{\mathrm{b}}$ Utrecht Institute of Linguistics OTS, Utrecht University, The Netherlands
}

Received 27 January 2016

Accepted 22 July 2016

\begin{abstract}
.
BACKGROUND: Despite various health promotion initiatives, unfavorable figures regarding Dutch truck drivers' eating behaviors, exercise behaviors, and absenteeism have not improved.

OBJECTIVE: The aim was to obtain a better understanding of the low level of effectiveness of current health interventions for Dutch truck drivers by examining to what extent these are tailored to the target group's particular mindset (focus of content) and health literacy skills (presentation of content).

METHODS: The article analyzes 21 health promotion materials for Dutch truck drivers using a two-step approach: (a) an analysis of the materials' focus, guided by the Health Action Process Approach; and (b) an argumentation analysis, guided by pragma-dialectics.

RESULTS: The corpus analysis revealed: (a) a predominant focus on the motivation phase; and (b) in line with the aim of motivating the target group, a consistent use of pragmatic arguments, which were typically presented in an implicit way.

CONCLUSIONS: The results indicate that existing health promotion materials for Dutch truck drivers are not sufficiently tailored to the target group's mindset and health literacy skills. Recommendations are offered to develop more tailored/effective health interventions targeting this high-risk, underserved occupational group.
\end{abstract}

Keywords: Workplace health promotion, health literacy, tailoring, argumentation, corpus analysis

\section{Introduction}

Over the last decade, various interventions have been developed to improve Dutch truck drivers' healthy lifestyle behaviors. These initiatives are motivated by both health and economic concerns. First, the Dutch trucking industry acknowledges that it is partly responsible for truck drivers' health, as the occupation places truck drivers at high risk for poor

\footnotetext{
*Address for correspondence: Anniek Boeijinga, MA, Centre for Language Studies, Radboud University Nijmegen, P.O. Box 9103, 6500 HD Nijmegen, The Netherlands. Tel.: +31 024 3611475; E-mail: a.boeijinga@let.ru.nl.
}

health outcomes [1]. The detrimental working conditions (e.g., time pressure, nonstandard working hours, prolonged periods of driving/sitting) are associated with overweight, musculoskeletal symptoms, diabetes, cardiovascular diseases, chronic fatigue, and work-related stress [2-4]. In addition, the working environment provides limited opportunities to exercise and to choose healthy food options [5-7]. The economic motive follows from the scenario that the Netherlands, with its 90,000 truck drivers, faces a serious truck driver shortage in the near future. Consequently, sustainable employability is a vital issue for the Dutch trucking sector. 
Despite various health promotion initiatives - such as the large-scale campaigns Beroepsvervoer Natuurlijk Alcohol Vrij (Professional Driving: Naturally Alcohol-Free, campaign period: 2004), Fit op de Rit (Fit for the Road, 2006-2007), the launch of the "EHBO-toolbox" (First aid toolbox for relaxation; 2010-2011), and the distribution of leaflets on diet, exercise, posture, fatigue, stress, and health and safety (from 2010 onwards) - health and lifestyle risks have remained. At present, $25.9 \%$ of the Dutch truck drivers are obese, compared to $10 \%$ of the overall workforce, while another $46.7 \%$ is overweight. These are alarming figures, since truck drivers with a higher BMI are significantly more often (23\%) and longer ( $>9$ days) absent from work than truck drivers with lower BMI scores (14\%) [7]. Research has further revealed that the vast majority of Dutch truck drivers reports not exercising enough (53\%) or not exercising at all $(14.2 \%)$, and being not $(40.2 \%)$, or to a limited extent $(40.4 \%)$ involved in sports activities. In addition, $60.2 \%$ of the Dutch truck drivers report a non- or infrequent intake of fruits and/or vegetables [7]. These unfavorable figures suggest that the current initiatives have not been effective in improving the lifestyle of Dutch truck drivers.

An important factor in enhancing the effectiveness of health communication interventions is tailoring. Health messages that are adapted to the unique characteristics of a person or a target group result in greater health behavior change than non-tailored health messages [8], especially those focusing on preventive behaviors such as physical activity and dietary change [9]. The unfavorable figures for health behaviors raise the question of whether the existing health messages are sufficiently tailored to the characteristics of this target group. In this paper, we investigate what changes Dutch interventions aim to achieve and what content they present to achieve these changes. We compare these communication strategies to theoretical insights into the determinants of health behavior [10] and into the skills people may need to effectively process these messages [11].

\subsection{HAPA: three mindsets on the road to behavior change}

Tailoring has been found to be more effective when guided by theoretical considerations, especially when the intervention is tailored to the stage of behavior change an individual is in [9]. An influential model for the stages of behavior change is the Health Action
Process Approach (HAPA) [10]. This model distinguishes three groups that differ with respect to their stage of change: "actors" (who already perform the desired behavior); "intenders" (who want to adopt the behavior but have not yet done so); and "nonintenders" (who have no intention of adopting the behavior).

The health figures for Dutch truck drivers suggest that there are few actors among this occupational group. Previous research [12] has indicated that, overall, Dutch truck drivers regard health as very important and manage to warrant a sense of good health by comparing their own health to that of people who are doing worse. As a result, personal health risks are downplayed (until symptoms can no longer be ignored). In addition, Dutch truck drivers were found to have negative associations with healthy living as they regard healthy eating and exercise behaviors as being at odds with a pleasurable life. Because of this low perceived health risk and expected negative outcomes, some truck drivers lack the motivation to adapt their lifestyle behaviors, qualifying them as non-intenders. The study indicated that there were also truck drivers who were motivated to live a healthier life; these intenders, however, indicated that they were unable to convert their intention into action due to the obstacles encountered within the work and personal environments. Factors specified included irregular working hours, lack of (exercise) facilities on the road, and demands from their family and social group that prohibit them from adopting healthy eating habits and exercising.

The group of truck drivers who currently do not show the desired behavior may thus consist of two different sub-groups that should be addressed differently. Non-intenders are considered to be in the motivation phase; as they are not yet motivated to adopt the promoted behavior, they may benefit from communication focusing on risk perception (to make sure they do not underestimate the health risks they run), realistic outcome expectancies (to provide a realistic yet attractive image of the outcomes of a more healthy lifestyle), and action self-efficacy (to strengthen the belief in their ability to initiate a more healthy lifestyle). Intenders, on the other hand, are considered to be in the volitional phase; they already intend to perform the desired behavior, but fail to translate this intention into action because they do not get started and/or their efforts are thwarted by unforeseen barriers or temptations along the road. Hence, they would benefit from health messages that focus on action planning (to specify the intended action and 
help them to get started), coping planning (to facilitate the anticipation of potential obstacles and ways to deal with these obstacles), and maintenance selfefficacy (to strengthen the belief in their ability to deal with the encountered obstacles) $[10,12]$. To assess to what extent the current materials cater to the needs of which target group, the first research question is: Which HAPA determinants are targeted in the current health promotion materials for Dutch truck drivers? (RQ1).

\subsection{Health literacy skills}

In addition to tailoring the content of health intervention to the target group's profile, attention should also be paid to the form. The target group's level of health literacy is highly relevant in this respect $[9,13]$. Health literacy involves "the cognitive and social skills which determine the motivation and the ability of individuals to gain access to, understand and use information in ways which promote and maintain good health" [14]. These skills comprise functional, interactive, and critical skills [15-17]. Functional skills involve the ability to apply the literacy (read/write) and numeracy skills needed to understand health information, whereas interactive skills involve the capacities to independently "obtain, perceive, recognize, comprehend, analyze, choose and value health information" [18]. Critical skills reflect the capacity to critically analyze health information and use it to exert greater control over life events and situations at both the individual and community level [15, 18, 19].

For health communications to be effective, they should be tailored to the health literacy skills of the target group [16, 20]. In general, Dutch truck drivers have a relatively lower level of education and lower socioeconomic status (SES) [2, 21], presumably corresponding with lower health literacy and poor health literacy skills $[16,20]$. This raises the question as to what extent the content provided in the health interventions poses too high demands on the target group's literacy skills. For instance, these materials may contain arguments to convince the target group that they run health risks due to their profession. How are these arguments presented and what skills are required to fully grasp their impact? A similar question could arise if these interventions contain instructions on how to perform the healthier behavior. What skills are required to understand these instructions and to act upon them? Therefore, the second research question is: What health literacy skills are required to process the content provided in the health interventions? (RQ2).

Answering these research questions may increase our understanding of the low level of effectiveness of existing health promotion initiatives targeting Dutch truck drivers and thereby provide insights for the development of more effective health interventions for this high-risk, underserved target group. In line with our objectives, the analysis consisted of two steps. The first step involved an analysis of the content, to examine on which HAPA determinants the materials focus. In the next step, we analyzed how this content is presented to the audience, and which demands this presentation poses on the audience's health literacy skills.

\section{Step 1: Analysis of HAPA focus}

Once institutional review board approval was obtained, a total of 21 health promotion materials for Dutch truck drivers were analyzed. We collected our data using the following criteria: all the available materials: (a) targeted Dutch truck drivers; (b) promoted health-related behaviors; and (c) had been used within the last 15 years (2000-2015). The obtained materials varied from large- to small-scale communications (including leaflets, brochures and campaign posters), ranging from 1 to 32 pages in length. Fifteen out of the 21 brochures encouraged desirable behavior (e.g., healthy body postures, eating patterns, exercise behaviors, and stress relaxation), the remaining six discouraged undesirable behavior (e.g., smoking and alcohol consumption). All health promotion materials contained images or photographs and were presented in print form. Our data collection did not yield any audio, audiovisual, or digital materials; print is still the most commonly used medium for workplace health promotion in the Dutch trucking industry. All the materials were produced by, or in collaboration with, organizations within the Dutch trucking industry - including occupational health services and the national institute for transport and logistics.

\subsection{Data analysis}

The focus areas of the health promotion materials were classified in terms of the theoretical constructs for health behavior change as defined by the HAPA [10]. In line with HAPA, we distinguished between determinants of the intention that are relevant for non- 
intenders and determinants of converting intention into action that are relevant for intenders. For the nonintenders, we distinguished attempts to increase the target group's perception of risk, and/or references to its membership of a high (or higher) risk group including: references to high probability, statistics, and percentages (risk perception); and attempts to influence the target group's outcome expectancies by focusing on the positive outcomes of the advocated behavior (outcome expectancies) and attempts to increase the reader's beliefs in being able to initiate the advocated behavior, and/or to help the reader to initiate the new behavior by advocating the behavior's feasibility or practicability by, for example, offering guidance or by giving general examples and tips on initiating the new behavior (action self-efficacy) as part of the motivation phase.

For the intenders, who are in the volition phase, we distinguished a focus on the specifics about how to implement the new, promoted behavior, the "when", "where" and "how" of the intended action (action planning); a focus on concrete scenarios of the advocated behavior - including the anticipation of barriers that may arise while engaging in and/or adhering to the advocated behavior and the generation of strategies for coping with these barriers (coping planning); and attempts to increase the audience's beliefs in being able to deal with barriers that arise while engaging in and adhering to the new, advocated behavior (maintenance self-efficacy).

All passages in the materials containing either explicit or implicit references to HAPA determinants were included. Images were included in the analyses if implicit (or non-verbal) references to HAPA determinants could be extracted from them. Passages referring to target groups other than truck drivers (e.g. forklift drivers, planners, or employers) were excluded from the analyses. For each intervention, we identified which HAPA determinants were focused upon. Given the differences in length of the health promotion materials, we decided to code if the HAPA determinants were used within one intervention, disregarding the frequency. The classifications were developed after extensive consultation between two raters, who first analyzed the materials independently.

\subsection{Results}

An overview of the focus of health promotion materials for Dutch truck drivers is given in Table 1. In the sections to follow, we will use translated examples to illustrate how the various HAPA determinants
Table 1

The HAPA determinants focused upon in health promotion materials for Dutch truck drivers

\begin{tabular}{lc}
\hline HAPA determinant & $\begin{array}{c}\text { Number of materials in which the HAPA } \\
\text { determinant is focused upon } n(\%)\end{array}$ \\
\hline Motivation phase & $18(85.7)$ \\
Action self-efficacy & $16(76.2)$ \\
Outcome expectancies & $12(54.5)$ \\
Risk perception & \\
Volition phase & $9(42.9)$ \\
Action planning & \\
\hline
\end{tabular}

were targeted in the materials. The original excerpts in Dutch can be obtained from the corresponding author.

\subsubsection{Action self-efficacy}

To strengthen the target audience's belief that it will be able to initiate the new, advocated behavior - that is, the target audience's action self-efficacy the vast majority of materials included a 'tips \& tricks' section. The presented tips range from general (e.g., get into a good driving position, or eat regularly three times a day) to more specific (e.g., spread only one slice of bread and put another slice on top of that). Besides tips \& tricks, a number of materials offered the reader a workshop (e.g., 'Quit Smoking' and 'Healthy Eating'), a lifestyle program (e.g., the 'Alcohol Control' program), coaching (e.g., by a relaxation coach, a personal trainer or mentor), or other forms of help and guidance in adopting lifestyle changes. Another intervention tried to encourage the readers' action self-efficacy by explicitly downgrading the level of effort it would take to engage in the advocated behavior:

Half an hour of exercise a day, five days a week, will take you a long way in the right direction. Well, and what is half an hour? Ten minutes of walking here, five minutes of biking there. It does not have to cost that much time and trouble. Because the gym is really not the only place to work on your fitness ... (Relaxation First Aid - Gezond Transport \& NISB)

\subsubsection{Outcome expectancies}

The reader's evaluation of the expected outcomes of a behavior can be positive or negative. To motivate their target group to act in line with the promoted behavior, the health materials commonly aimed to influence the truck drivers' outcome expectancies by stressing the advantages of the advocated behavior. In a brochure on healthy eating, for instance, these 
advantages were listed under the heading "Benefits of healthier food and drink" and included amongst others "you'll feel fitter", "you'll reduce the risk of cardiovascular diseases and diabetes", and "you'll look better" (Healthy eating - ArboNed).

The reported advantages generally related to truck drivers' health and/or work performance (e.g., being more alert and working more concentrated when reducing your alcohol intake). Only one intervention overtly communicated advantages connected to truck drivers' personal/family lives, by implying that a healthier lifestyle also affects one's children and (future) grandchildren: "you are not just doing it for yourself” (Also enjoying work? - STL).

\subsubsection{Risk perception}

About half of the materials included passages on risk perception. Instead of focusing on the positive consequences of the desired behavior (i.e., outcome expectancies), a number of materials focused upon the negative consequences of the current, undesirable behavior (e.g., if you don't lose weight, you'll run the risk of developing illnesses and of no longer fitting behind the wheel... ). Another form of increasing the reader's perceived chance of a health problem or risk is by addressing the characteristics of being a truck driver:

What is it that a truck driver does all day? Right, sitting. But, that is exactly what the body is not made for. Your back, shoulders and/or upper legs will start protesting, sooner or later. (Also a welladjusted driver seat? - STL)

In addition to references to the nature of their work, some materials included statistics to communicate truck drivers' increased threat to health risks: "In 10 to 20 percent of the traffic accidents in our country that involve trucks, fatigue plays a role (Dozing away? Not while you' re on the way! - BGZ)". Another, more implicit way in which some materials included levels of risk communication is the use of test sections. In one intervention, for example, the reader was asked to measure his or her Body Mass Index (BMI) and waist circumference - followed by a table indicating the person's personal risk level, for example: "ok (pot)belly, but be aware - the danger zone is in sight" (Such a healthy appetite as well? - STL).

\subsubsection{Action planning}

As previously stated, the tips in the tips \& tricks sections ranged from the general to the more specific. Differing from general tips to help the reader initiate the new behavior (action self-efficacy), action planning involves passages and/or tips on the new behavior's specifics. Nine of the 21 selected materials included tips with specifics on the when, where and/or how of the intended action. The following exercise tips provide a good example:

- Little time to exercise during the workweek? Take a bold step and venture out with friends or family during the weekend. There are some great walking and cycling routes on the Internet.

- Make good use of your resting times on the road! Go for a 10-minute walk on the parking lot after your coffee or meal, for example. If you do this three times a day, you'll be getting enough exercise. And take a look at the 10 exercises in this booklet. (Relaxation First Aid - Gezond Transport \& NISB).

Passages particularly referring to the "how" were those involving instructions on how to perform the desired behavior, often accompanied by images.

Summarizing then, the selected health promotion materials show a predominant focus on HAPA determinants pertaining to the motivation phase; action self-efficacy, outcome expectancies, and risk perception. Only nine of the 21 materials focused on the volition phase by including information on action planning. Although some of the materials acknowledged the challenges that truck drivers face in obtaining and maintaining a healthier lifestyle, none of the materials referred to potential barriers that may arise and coping strategies to overcome these barriers (coping planning), or to the beliefs about one's ability to deal with these barriers (maintenance selfefficacy).

\section{Step 2: Argumentation analysis}

In line with the aim of motivating their target group (see findings step 1), the materials consistently used argumentation in order to persuade the reader to engage in (e.g., healthy diet) or refrain from (e.g., drink-driving) certain behaviors. There is good reason for such an approach: Persuasion achieved by a careful evaluation of arguments - that is, through central processing - is believed to result in strong and stable attitudes that are relatively good predictors of subsequent behavior [22-24]. In their analysis of 20 public information brochures, Schellens and De Jong [11] show that arguments in persuasive brochures are often presented, or disguised, as factual information. 
As a result, the audience has to reconstruct what information can serve as an argument. In order to assess the quality of the argument, the audience has to identify what type of argument it is. Different types of argumentation (for example, argumentation from analogy and argumentation from authority) are based on different relations between the argument and the claim and, thus, need to be tested against different evaluation criteria $[11,25]$.

In short, the central processing of regular health promotion materials may pose considerable demands on their audience's cognitive capacities and requires skills at the level of (at least) functional and interactive health literacy as the audience must be willing and able to analyze and evaluate different types of argumentation on the basis of what is presented as an informative text. The lack of impact of the current interventions aimed at Dutch truck drivers may be the result of a similarly 'cloaked' presentation of their argumentative content being beyond the target group's health literacy skills. Therefore, the second step involved an analysis of the materials' argumentative content, examining the presentation of the arguments to infer what level of health literacy skills is required for evaluating the arguments.

\subsection{Data analysis}

The argumentation analysis was guided by the pragma-dialectical approach [26-28], due to its systematic guidelines for analyzing and evaluating argumentation [11]. Pragma-dialectics distinguishes three types of argumentation: symptomatic argumentation, comparison argumentation, and causal argumentation. These types of argumentation differ from one another in how they relate the argument to the standpoint. In argumentation based on a symptomatic relation, "a standpoint is defended by citing in the argument a certain sign, symptom, or distinguishing mark of what is claimed in the standpoint" [25]. For a careful evaluation of symptomatic argumentation, the most important critical questions to ask are: "Is the characteristic indeed typical of the property?"; and "Is the characteristic not also typical of something else?" [29]. Subtypes of symptomatic argumentation are argumentation from example, argumentation from authority, and argumentation based on the meaning of a term.

In argumentation based on a relation of analogy or comparison, "a standpoint is defended by showing that something referred to in the standpoint is similar to something that is cited in the argumentation, and that on the grounds of this resemblance the standpoint should be accepted" [25]. When evaluating comparison argumentation, the most important critical questions are: "Are the things that are being compared actually comparable?"; "Are there enough relevant similarities between the things that are being compared?"; and "Are there any relevant differences between the things that are being compared?" [29]. In addition to argumentation from analogy, pragma-dialectics distinguishes argumentation of figurative comparison and argumentation based on the principle of justice as subtypes of comparison argumentation.

In argumentation based on a causal relation, "a standpoint is defended by making a causal connection between the argument and the standpoint, such that the standpoint, given the argument, ought to be accepted on grounds of this connection" [25]. The most important evaluation questions associated with comparison argumentation are: "Does the established cause, in fact, lead to the mentioned result?"; "Are there any factors that must be present together with the proposed cause to create the mentioned result?"; and "Could the proposed result be caused by something else as well?" [29]. In addition to argumentation from cause to effect and argumentation from effect to cause, pragmatic argumentation is categorized as a special subtype of causal argumentation.

All passages in the materials containing explicit, implicit or non-verbal (i.e. photos or images) argumentation for the position in question were included. For each intervention, we identified whether argumentation was used and, if so, how the (different types of) arguments were presented, and how this affects the evaluation process. As in step 1, the classifications were developed after extensive consultation between two raters.

\subsection{Results}

In this section, we will illustrate how the argumentation in the health promotion materials targeting Dutch truck drivers was presented and what implications this has for the evaluation of these materials. As different evaluation questions apply to different argument types, we discuss the results on the basis of the different types of argumentation. In line with Schellens and De Jong [11], pragmatic argumentation, argumentation from cause to effect, argumentation from example, and argumentation from authority were the argument types most frequently used in the materials. 


\subsubsection{Pragmatic argumentation}

In pragmatic argumentation, a behavior is promoted or discouraged on the basis of its desirable (pro) or undesirable (con) consequence - resulting in the following argument scheme [30]:

Action X should (not) be performed

Because: Action $\mathrm{X}$ leads to $\mathrm{Y}$

And: $\mathrm{Y}$ is (un)desirable

In the following excerpts from one of the interventions on healthy eating, both the positive and negative variants of pragmatic argumentation are used respectively.

[... ] If you learn better ways to resist unhealthy food temptations, you will definitely feel healthier and fitter.

And:

If you (continue to) eat unhealthily, you will notice that immediately in your fitness and weight. [...]

\section{(Healthy eating - ArboNed)}

In these examples, as in all instances of pragmatic arguments in these materials, parts of the argument were left implicit. For instance, the conclusion that one should resist, or learn to resist, unhealthy food temptations is not stated. Similarly, the desirability or undesirability of "feeling healthier and fitter" and "immediately noticing it in your fitness and weight" are not expressed. Even though the required inferences may seem straightforward, one has to keep in mind that they not only have to be inferred but also evaluated. For the arguments to hit home, the target audience has to consider the predicted consequence not only as desirable or undesirable, but also as the effect of the proposed cause. In a number of materials, as in the second example, the predicted consequence was presented in such a vague and implicit manner ("immediately noticing it in your fitness and weight") that it imposes difficulties for readers assessing its desirability or undesirability, and its probability.

\subsubsection{Argumentation from cause to effect}

In its typical form, argumentation from cause to effect suggests that one thing leads to another; in other words, it suggests that there is a causal relation between a cause and the effect that is mentioned in the standpoint [25]:

$\mathrm{Y}$ is true of $\mathrm{X}$

\section{Because: $\mathrm{Z}$ is true of $\mathrm{X}$}

\section{And: $\mathrm{Z}$ leads to $\mathrm{Y}$}

Argumentation from cause to effect is often used to support statements about the probability of a consequence, as in the following excerpt in which truck drivers' typical working conditions are causally linked to (future) back problems:

Heavy lifting. Shoving roll cages. Prolonged periods of sitting. Unloading the truck. Whether working on the truck, in a warehouse or at the office, your back is suffering. Especially if you made it a habit to use your back incorrectly. Because if you persist with these habits long enough, your back will start protesting at some point. And your back will find no problem in maintaining its protest for a long time. (Such a healthy back as well? - STL)

As excerpts like these refer to the characteristics of being a truck driver, one could argue that these particular instances are forms of symptomatic argumentation. The ambiguity lies in the fact that both causal argumentation and symptomatic argumentation are expressed in the form "Y is true of $X$, because $Z$ is true of $X$ " and that the linking premise (" $Z$ leads to $Y$ ", or " $\mathrm{Z}$ is symptomatic of $\mathrm{Y}$ ") is typically left unexpressed [29] - leaving the reconstruction and attribution of the linking premise to the reader. As the attribution of the (ambiguous) linking premise is a prerequisite for answering the associated critical questions (e.g., Does the proposed cause (Z) indeed lead to the mentioned result (Y)?), this results in ambiguity about how the argument should be evaluated.

Considering that from the fact that truck drivers are working in challenging conditions, the deduction is made that this will lead to undesirable health consequences, we decided to consistently interpret such accounts as forms of causal argumentation.

\subsubsection{Argumentation from example}

In argumentation from example, a number of separate cases, or examples, are presented as indicative of something in general [25]:

$\mathrm{Y}$ is true of $\mathrm{X}$

Because: $\mathrm{Z}$ is true of $\mathrm{X}$

And: $\mathrm{Z}$ is exemplary of $\mathrm{Y}$

In the materials, argumentation from example was used to support statements about the feasibility of 
the promoted behavior (e.g., by giving examples (or tips) on how to initiate the behavior) or for supporting statements about the desirability or undesirability of a consequence, for example:

Whether you are a chain smoker or a social smoker, for your health it is very important that you quit smoking. [...]

\section{What are the benefits of quitting smoking?}

- Your fitness improves

- Your sense of smell and taste improves

- You are less likely to get sick or get a cold

$$
\text { [... ] (Quit smoking - ArboNed) }
$$

The desirability of smoking cessation is supported by exemplary benefits of the consequences of smoking cessation. Note that, again, in this case, as in all cases of argumentation from example, the linking premise is left implicit and must be reconstructed by the reader in order to test the argumentation against critical questions as: Are the presented examples (Z) indeed exemplary for the matter in question $(Y)$ ? and Are there enough separate cases, or examples, (Z) mentioned?

\subsubsection{Argumentation from authority}

In argumentation from authority, the agreement of a supposed authority with a statement is presented as a guarantee for the statement's acceptability $[31,32]$ :

Statement $\mathrm{X}$ is acceptable

\section{Because: Authority Y says X}

And: The expertise of Y guarantees the acceptability of $\mathrm{X}$

The use of argumentation from authority throughout the selected health promotion materials can be divided into two categories: In about half of the materials a reference was made to the sender's authority, for example:

\section{About ArboNed}

ArboNed is a leading and professional occupational health service, which focuses on improving the sustainable employability of employees, resulting in a reduction of absenteeism within companies and institutions. Daily, we provide services to 80,000 employers and more than 1 million employees. Among our customers are SME entrepreneurs, multinational corporations, institutions, and governments. (More relaxation - ArboNed)

In these cases, it is not clear to which particular statement the authority relates; the authority argumentation seems to be used in support of the whole material rather than in support of a specific statement. Subsequently, it is not clear to which statements the critical questions relate, which makes it very hard for the reader to assess whether the mentioned authority $(Y)$ is indeed an expert with regard to the statement $(\mathrm{X})$, and whether the expertise of the authority $(\mathrm{Y})$ is sufficient to guarantee the acceptability of the statement (X). Note also that one could argue that the sender, while referring to its own authority and capacity, is arguing by authority rather than from authority $[31,32]$.

In other materials, testimonials from truck drivers were used to support statements relating to the desirability and/or feasibility of the behavior:

'A break away with the family: that's what we do every summer. And later, hopefully with the grandchildren as well. Therefore, I do my best to stay as fit as possible. Since the eldest, I've started to eat more healthily for example. And to exercise more.' (Also enjoying work? - STL)

In line with Schellens and De Jong [11], we interpreted such instances as argumentation from authority as "the testimonial provider's membership of the target group and the reader's possibility of identification with him or her give the testimonial provider the authority of someone who speaks from experience". In addition to verbal accounts, nonverbal accounts of testimonials were frequently used: In photographs of truck drivers engaging in and enjoying the promoted behavior (e.g., a trucker who is walking with the dog, or a trucker who is playing soccer with his kids) the portrayed truck driver is - as an authority of experience - showing both the feasibility and desirability of the promoted behavior. Thus, the argumentation is expressed in the form "Statement $\mathrm{X}$ is acceptable, because authority $\mathrm{Y}$ shows (instead of says) X". The nonverbal accounts of authority argumentation are highly implicit and, consequently, place high demands on the reader's cognitive skills in terms of the evaluation and processing of these arguments.

Summarizing then, a common aspect of the arguments employed in the health materials targeting Dutch truck drivers was that the linking premise was left implicit. The linking premise is, however, 
a crucial factor in evaluating the arguments as it indicates which argument scheme links the explicit premise to the standpoint. In other words, the audience has to infer what warrant connects the evidence to the claim. In addition, the link to the claim about the behavior (e.g., ... and therefore you should eat more healthily), is also often not expressed. As a result of the implicit presentation of the arguments, a careful evaluation of the arguments requires the audience to reconstruct the argumentation links in order to be able to answer the associated critical questions.

\section{Discussion}

The aim of this analysis was to assess which health behavior determinants are targeted in current health interventions for Dutch truck drivers (RQ1) and which demands the argumentative content of these interventions pose on the cognitive capacities of the target group (RQ2). The analysis of the targeted determinants revealed a predominant focus on determinants pertaining to the motivation phase of HAPA. The three determinants of the intention action self-efficacy, outcome expectancies, and risk perception - were the three most frequently addressed issues. In fewer than half of the interventions, attention was paid to action planning; the other factors that may help people convert intentions into actions, coping planning and maintenance efficacy were not addressed in any of the interventions.

These results suggest that the developers of these materials consider Dutch truck drivers as nonintenders. In their opinion, the target audience needs to be motivated to adopt a more healthy lifestyle. This assumption was confirmed during a meeting where we shared our preliminary findings with both applied researchers in the field of health communication and experts within the Dutch sector of transport and logistics; the vast majority of the participants believed lack of motivation to be the main cause for Dutch truck drivers' unfavorable and unchanging lifestyle behaviors. Previous research [12], however, suggests that there are Dutch truck drivers who have the intention to adapt their lifestyle and would benefit from a focus on planning strategies, i.e. action planning (specifying "when", "where", and "how") and coping planning (imagining what obstacles might exist and how to deal with them). In view of the challenges and obstacles inherent to their work context, planning strategies can facilitate truck drivers in translating their good intentions into actions. The investigated health interventions thus appear to be inadequately tailored to the particular mindset of what might be a considerable part of the target group.

With respect to the way in which the arguments were presented, the results in this study replicate those of Schellens and De Jong [11]: Despite their persuasive intent, the health promotion materials have a rather informative look as a result of parts of the argumentation being left implicit. One of the underlying reasons for such an informative cloak may be to prevent evoking reactance. The interventions suggest changes in behaviors, thereby threatening the person's liberty of action and self-determination [33]. Such a perceived threat of one's autonomy can evoke reactance towards the persuasive message, which may lead to a failure to obtain the intended effect or even a boomerang effect [34]. An informative 'look' may disguise the persuasive intent and, thereby, potentially reduces reactance. However, such an approach poses high demands on the reader's cognitive resources. For if the reader wants to evaluate the argumentation against the critical questions relevant to the particular type of argument, which is demanding in itself, he or she has to identify the lines of argumentation by explicating the unexpressed linking premises and conclusions in order to be able to do so. These demands on the cognitive skills of the audience may be too high for target groups with lower health literacy, such as truck drivers. Thus, current health promotion materials for Dutch truck drivers do not cater to the needs of intenders content-wise (focusing on the wrong determinants), nor to the needs of non-intenders form-wise (too difficult to process).

\subsection{Limitations}

While the findings presented here are indicative, this study is not without its limitations. As previously indicated, the corpus consisted of print materials only. The data collection did not yield any digital, audio or audiovisual materials. In terms of presentation, we paid no attention to the visual formatting. That is, we did not take into consideration the visual effects on the materials' intelligibility and comprehensibility. A second limitation is the lack of statistics on truck drivers' reading levels and actual readership of these interventions. All of the health promotion materials were systematically distributed among trucking employees (small-scale) or Dutch truck drivers (large-scale). Yet, a systematic distribution does not necessarily imply a systematic consumption of the materials; if materials are not sufficiently 
stimulating to attract and keep the attention of the target group, the message will not have any impact at all $[9,35]$. This lack of attention may offer an additional explanation for the materials' low impact. We therefore suggest future research to also incorporate health promotion materials' perceived attractiveness. More insight in the reading grade levels of Dutch truck drivers may enable matching the health materials' language and legibility to the drivers' reading abilities. For the sake of reliability and validity, we further recommend more quantitative approaches to test the effectiveness of health promotion materials for Dutch truck drivers.

\section{Conclusion}

In spite of numerous health promotion activities, many Dutch truck drivers persist in maintaining a relatively unhealthy lifestyle. This lack of impact may be caused by the fact that the current interventions are insufficiently tailored to the stage of behavior change that at least part of this target group finds itself in, as well as to its cognitive capacities. First, the interventions are geared to the needs of nonintenders, whereas there are indications that there are a considerable number of intenders among the target group. Second, the arguments provided in the interventions are presented in a way that requires considerable effort and skills to identify and evaluate them. These findings indicate that health promotion for truck drivers would benefit from: (a) an additional focus on action planning and coping planning; and (b) the use of approaches, or formats, that require lower health literacy skills. Future (quantitative) research should be conducted to further verify our findings, including their generalizability for truck drivers from other countries, and to test the promise of more tailored approaches to health promotion for truck drivers.

\section{Acknowledgments}

The authors thank the Dutch national institute for transport and logistics (Sectorinstituut Transport \& Logistiek, STL) and the Dutch occupational health and safety organization ArboNed for their collaboration and assistance during the data collection. This study was funded by the Netherlands Organization for Scientific Research (NWO/ZonMW); project BGRL-11-15.

\section{Conflict of interest}

The authors have no conflict of interest to report.

\section{References}

[1] Apostolopoulos Y, Sönmez S, Shattell MM, Gonzales C, Fehrenbacher C. Health survey of U.S. long haul truck drivers: Work environment, physical health, and healthcare access. Work 2013;46:113-23.

[2] Van der Beek A. World at work: Truck drivers. Occup Environ Med 2012;69:291-5.

[3] Van der Hulst M. Long workhours and health. Scand J Work Environ Health 2003;29:171-88.

[4] Härmä M. Workhours in relation to work stress, recovery and health. Scand J Work Environ Health 2006;32: 502-14.

[5] Apostolopoulos Y, Sönmez S, Shattell MM, Haldeman L, Strack R, Jones V. Barriers to truck drivers' healthy eating: Environmental influences and health promotion strategies. Journal of Workplace Behavioral Health 2011;26(2):122143.

[6] Apostolopoulos Y, Shattell MM, Sönmez S, Strack R, Haldeman L, Jones V. Active living in the trucking sector: Environmental barriers and health promotion strategies. Journal of Physical Activity and Health 2012;9:259-69.

[7] Trendrapport 2013 [Internet]. Gouda: Gezond Transport; 2013 [cited 2015 Mar 20]. Available from: http://www. stlwerkt.nl/VTL/media/Media-Library/Gezond\%20

Transport/trendrapport-gezond-transport-eindversiedecember-2013_met-omslag1.pdf

[8] Lustria MLA, Noar SM, Cortese J, Van Stee SK, Glueckauf RL, Lee, J. A meta-analysis of web-delivered tailored health behavior change interventions. Journal of Health Communication 2013;18:1039-69.

[9] Noar SM, Benac CN, Harris MS. Does Tailoring matter? Meta-analytic review of tailored print health behavior change interventions. Psychological Bulletin 2007; 133(4):673-93.

[10] Schwarzer R. Modeling health behavior change: How to predict and modify the adoption and maintenance of health behaviors. Applied Psychology 2008;57(1):1-29.

[11] Schellens PJ, De Jong M. Argumentation schemes in persuasive brochures. Argumentation 2004;18:295-23.

[12] Boeijinga A, Hoeken H, Sanders J. Health promotion in the trucking setting: Understanding Dutch truck drivers' road to healthy lifestyle changes. Work 2016;55(2): 385-97.

[13] Bernhardt J, Cameron KA. Accessing, understanding, and applying health communication messages: The challenge of health literacy. In: Thompson L, Dorsey AM, Miller KI, Parrott R, editors. Handbook of health communication. Mahwah (NJ): Erlbaum; 2003. pp. 583-605.

[14] Health Promotion Glossary [Internet]. Geneva: World Health Organization (WHO); 1998 [cited 2015 Mar 12]. Glossary No.: 98.1. Available from: http://www.who.int/hea 1thpromotion/about/HPR\%20Glossary\%201998.pdf

[15] Nutbeam D. Health literacy as a public health goal: A challenge for contemporary health education and communication strategies into the 21 st century. Health Promotion International 2000;15(3):259-67.

[16] Nutbeam D. The evolving concept of health literacy. Social Science \& Medicine 2008;67:2072-8. 
[17] Nutbeam D. Defining and measuring health literacy: What can we learn from literacy studies? Int J Public Health 2009;54:303-5.

[18] Mårtensson L, Hensing G. Experiences of factors contributing to women's ability to make informed decisions about the process of rehabilitation and return to work: A focus group study. Work 2012;43:237-48.

[19] Christmann S. Health Literacy and Internet: Recommendations to promote Health Literacy by the means of the Internet. EuroHealthNet [cited 2016 Jan 12]. Available from: http://eurohealthnet.eu/sites/eurohealthnet.eu/files/ publications/pu_8.pdf

[20] Twickler TB, Hoogstraaten E, Reuwer A, Singels L, Essink-Bot ML. Laaggeletterdheid en beperkte gezondheidsvaardigheden vragen om een antwoord in de zorg [Low literacy and low(er) health literacy ask for an answer from the health sector]. Nederlands Tijdschrift voor Geneeskunde 2009; 153:A250. Dutch.

[21] Fact sheet: Land transport [Internet]. Dublin: European Foundation for the Improvement of Living and Working Conditions (EFILWC); 2008 [cited 2009 Dec 13]. Available from: http://www.eurofound.europa.eu/pubdocs/2008/149/ en/1/EF08149en.pdf

[22] Petty RE, Cacioppo JT. Communication and Persuasion: Central and Peripheral Routes to Attitude Change. 1st ed. New York: Springer; 1986.

[23] Petty RE, Haugtvedt CP, Smith SM. Elaboration as a determinant of attitude strength: Creating attitudes that are persistent, resistant, and predictive of behavior. In: Petty RE, Krosnick JA, editors. Attitude Strength: Antecedents and Consequences. 1st ed. Mahwah (NJ): Erlbaum; 1995. pp. 93-130.

[24] Glasman LR, Albarracín D. Forming attitudes that predict future behavior: A meta-analysis of the attitude-behavior relation. Psychological Bulletin 2006;132(5):778-822.

[25] Van Eemeren FH, Grootendorst R, Snoeck Henkemans AF. Argumentation: Analysis, evaluation, presentation. 1st ed. Mahwah (NJ): Lawrence Erlbaum; 2002.

[26] Van Eemeren FH, Grootendorst R. Argumentation, Communication, and Fallacies: A Pragma-dialectical Perspective. Hillsdale (NJ): Lawrence Erlbaum; 1992.
[27] Garssen B. Argumentatieschema's in pragma-dialectisch perspectief. Een theoretisch en empirisch onderzoek [Argument schemes from a pragma-dialectical perspective. A theoretical and empirical study]. Amsterdam: IFOTT Amsterdam; 1997.

[28] Garssen B. Argument Schemes. In: Van Eemeren FH, editor. Crucial Concepts in Argumentation Theory. Amsterdam: Amsterdam University Press; 2001. pp. 81-99.

[29] Hitchcock DL, Wagemans JHM. The pragma-dialectical account of argument schemes. In: Feteris ET, Garssen BJ, Snoeck Henkemans AF, editors. Keeping in touch with pragma-dialectics. Amsterdam: Benjamins; 2011. pp. 185205.

[30] Van Poppel L. The strategic function of variants of pragmatic argumentation in health brochures. Journal of Argumentation in Context 2012;1(1):97-112.

[31] Pilgram R. A doctor's argumentation by authority as a strategic manoeuvre. In: Van Eemeren FH, Garssen B, Godden D, Mitchell G, editors. Proceedings of the 7th Conference of the International Society for the Study of Argumentation. Amsterdam: Rosenberg/Sic Sat; 2011. pp. 1527-37.

[32] Pilgram R. Strategisch manoeuvreren in medische consultatie. Een pragma-dialectische analyse van autoriteitsargumentatie van de arts [Strategic maneuvering in medical consultation. A pragma-dialectical analysis of a doctor's argumentation by authority]. Tijdschrift voor Taalbeheersing 2012;34(2):168-81. Dutch.

[33] Hall SA. Symposium on ethics and public health: Should public health respect autonomy? Journal of Medical Ethics 1992;18:197-201.

[34] Kim S, Levine TR, Allen M. The intertwined model of reactance for resistance and persuasive boomerang. Communication Research 2014;1-21.

[35] Donohew L, Lorch EP, Palmgreen P. Applications of a theoretic model of information exposure to health interventions. Human Communication Research 1998;24:454-68. 